\title{
Short-course radiotherapy promotes pro-inflammatory macrophages via extracellular vesicles in human rectal cancer
}

\author{
Victoria Stary (D) , ${ }^{1}$ Brigitte Wolf (D) , ${ }^{1}$ Daniela Unterleuthner, ${ }^{2}$ Julia List (D) , \\ Merjem Talic, ${ }^{1}$ Johannes Laengle (D) , ${ }^{1}$ Andrea Beer (D) , ${ }^{3}$ Johanna Strobl (D) , ${ }^{4}$ \\ Georg Stary (D) , ${ }^{4}$ Helmut Dolznig (D) , ${ }^{2}$ Michael Bergmann (D) ${ }^{1}$
}

To cite: Stary V, Wolf B, Unterleuthner $\mathrm{D}$, et al. Shortcourse radiotherapy promotes pro-inflammatory macrophages via extracellular vesicles in human rectal cancer. Journal for ImmunoTherapy of Cancer 2020;8:e000667. doi:10.1136/ jitc-2020-000667

- Additional material is published online only. To view please visit the journal online (http://dx.doi.org/10.1136/jitc2020-000667).

Accepted 02 July 2020

Check for updates

(c) Author(s) (or their employer(s)) 2020. Re-use permitted under CC BY-NC. No commercial re-use. See rights and permissions. Published by BMJ.

${ }^{1}$ Division of General Surgery, Department of Surgery, Comprehensive Cancer Center, Medical University of Vienna, Vienna, Vienna, Austria ${ }^{2}$ Institute of Medical Genetics, Medical University of Vienna, Vienna, Vienna, Austria ${ }^{3}$ Department of Pathology, Medical University of Vienna, Vienna, Vienna, Austria ${ }^{4}$ Department of Dermatology, Medical University of Vienna, Vienna, Vienna, Austria

\section{Correspondence to} Dr. Michael Bergmann; michael.bergmann@ meduniwien.ac.at

\section{ABSTRACT}

Background Tumor-associated macrophages (TAM) constitute the most abundant immune cells in the tumor stroma initiating pro-inflammatory (M1) or immunosuppressive (M2) responses depending on their polarization status. Advances in tumor immunotherapy call for a detailed understanding of potential immunogenic mechanisms of irradiation routinely applied in rectal cancer patients.

Methods To test the effects of radiotherapy on TAM, we ex vivo irradiated tissue samples of human rectal cancer and assessed the phenotype by flow cytometry. We furthermore evaluated the distribution of leucocyte subsets in tissue sections of patients after short-course radiotherapy and compared findings to non-pretreated rectal cancer using an immunostaining approach. Organotypic assays (OTA) consisting of macrophages, cancer-associated fibroblast and cancer cell lines were used to dissect the immunological consequences of irradiation in macrophages.

Results We demonstrate that short-course neoadjuvant radiotherapy in rectal cancer patients is associated with a shift in the polarization of TAM towards an M1like pro-inflammatory phenotype. In addition, ex vivo irradiation caused an increase in the phagocytic activity and enhanced expression of markers associated with stimulatory signals necessary for T-cell activation. In OTA we observed that this alteration in macrophage polarization could be mediated by extracellular vesicles (EV) derived from irradiated tumor cells. We identified high mobility group box 1 in EV from irradiated tumor cells as a potential effector signal in that crosstalk.

Conclusions Our findings highlight macrophages as potential effector cells upon irradiation in rectal cancer by diminishing their immunosuppressive phenotype and activate pro-inflammation. Our data indicate that clinically applied short-term radiotherapy for rectal cancer may be exploited to stimulate immunogenic macrophages and suggest to target the polarization status of macrophages to enhance future immunotherapeutic strategies.

\section{INTRODUCTION}

Since the introduction of immune checkpoint blockade, immunotherapy has become an attractive therapeutic option in cancer. ${ }^{1-3}$ Irradiation, used as standard therapy in a number of solid malignancies, induces immunogenic cell death (ICD) by the release of damage-associated pattern (DAMP). ${ }^{4}$ Studies based on murine models indicated that irradiation-induced DNA damage of tumor cells elicited an antitumor immune response. ${ }^{5}$ It was shown that alterations of the infiltrating immune cells by irradiation might be augmented, when combined with immunemodulating drugs. ${ }^{6-8}$ A detailed understanding of the impact of radiotherapy on the immune system in humans should allow application of radiotherapy as a part of novel immunotherapeutic concepts. However, little is known about the detailed regulation of the immunogenic effect of irradiation in clinical settings.

Macrophages are one of the most abundant immune cell subsets in tumor tissue ${ }^{910}$ and play a key role in the cancer microenvironment. $^{11}{ }^{12}$ Tumor-associated macrophages (TAM) are functionally diverse ${ }^{13}$ and display high plasticity upon immunological stimuli. ${ }^{14}{ }^{15}$ The concept of M1 and M2 macrophages was introduced to describe the heterogeneity of this cell subset. ${ }^{16}$ M1-like macrophages possess the capacity to clear infections in support of a $\mathrm{T}$ helper type 1 (Th1) immune response ${ }^{17}$ whereas M2-like macrophages respond in general to Th2 cytokines and are strongly enriched in the tumor microenvironment. ${ }^{18}$ The concept of $\mathrm{M} 1 / \mathrm{M} 2$ has been challenged and is seen as an oversimplified approach to the phenotype of macrophages but can be viewed as a linear scale on which M1 and M2 present two extremes. ${ }^{19}$ TAM recognize DAMP and respond by producing a variety of cytokines and growth factors to promote innate and 
adaptive immunity. ${ }^{9} 182021$ In response to these signals, macrophages are able to undergo reprogramming with enhanced antitumor features making them an attractive target for anticancer therapies. ${ }^{22}{ }^{23}$ There are conflicting results with respect to the effect of irradiation on the macrophage phenotype. Klug et al demonstrated in a murine model of breast cancer and human pancreatic cancer that low-dose irradiation (2 Gy) induced repolarization of M2-like macrophages to M1-like macrophages via induction of nitric oxide synthase (iNOS) ${ }^{24}$ Moreover, expression of iNOS correlated with vessel normalization and an influx of $\mathrm{CD}^{+} \mathrm{T}$ cells suggesting a tumor ablative as well as pro-inflammatory effect of repolarized macrophages. Upregulation of iNOS was also observed in murine prostate cancer, which has been irradiated with up to $25 \mathrm{~Gy} .{ }^{25}$ Similarly, agonists of the toll-like receptor further stimulated the M1 phenotype of macrophages and enhanced the antitumor effects of irradiation in a murine model of breast cancer. ${ }^{26}$ Other studies suggested that irradiation of tumors was associated with a more immunosuppressive phenotype of TAM. ${ }^{27-29}$ Jones et al found that the depletion of macrophages by an anti-CSF antibody greatly increased tumor ablation upon irradiation (10 Gy) in murine tumors generated from a colorectal and a pancreatic cell line. Obviously, the effect of irradiation appears to depend on the model, irradiation dose, tissue as well as on the investigated time point after irradiation. However, despite the controversial reports, an important role for TAM in response to radiotherapy seems evident.

More recently, extracellular vesicles (EV) have attracted attention in mediating signals to immune cells. EV are rich in molecular cargos and are emerging as critical messengers in the cell-to-cell crosstalk. They contain a variety of small signaling molecules, which can be transferred to other cell types to modulate cell functions. ${ }^{30-33}$ Thus, we hypothesized that $\mathrm{EV}$ might be involved in macrophages regulation in the tumor microenvironment in irradiated cells. Using a clinically relevant approach, we show that short-course irradiation increased the proportion of M1-like TAM in human rectal cancer tissue. Primary short-term cultures and organotypic tumor assays (OTA) consisting of tumor cell lines, macrophages and cancer-associated fibroblasts allowed to further dissect irradiation-induced changes in colorectal TAM. Using irradiated tumor cell lines, we demonstrate that EV are able to mediate irradiation-induced repolarization of macrophages.

\section{METHODS}

\section{Patients and tissue material}

Patients with clinical T3 rectal cancer (patients characteristics, online supplementary table 1) received neoadjuvant hyperfractionated radiotherapy over the course of 5 days within the frame of a controlled clinical study. ${ }^{34}$ As a control group, we used historical surgical tumor specimen of 25 non-pretreated rectal cancer lesions of patients from the same institution with no history of irradiation therapy or cytoablative treatment. For immunofluorescence and immunohistochemical stainings, surgical paraffin-embedded specimen of the cancer lesions were cut in $5 \mu \mathrm{m}$ sections and mounted on slides. For ex vivo cultures and subsequent flow cytometric stainings, rectal cancer tissue was obtained from 10 patients with histologically verified rectal cancer with no history of irradiation therapy or cytoablative treatment. Studies involving patient material were performed according to the Declaration of Helsinki and approved by the local ethics committee of the Medical University of Vienna (1374/2014). For OTA, HCT116 (CCL-147) and DLD-1 (CCL-221) were purchased from ATCC. Peripheral blood mononuclear cells for macrophage differentiation were isolated from healthy blood donors.

\section{Primary ex vivo cultures of leucocytes and flow cytometry}

Tissue samples of non-irradiated rectal cancer were minced, resuspended in RPMI 1640 medium with 5\% fetal bovine serum and plated in a $50 \mathrm{~mm}$ petri dish. Irradiation protocol was applied as indicated below. After 3 hour of incubation $\left(37^{\circ} \mathrm{C}, 5 \% \mathrm{CO}_{2}\right)$, a single-cell suspension from cancer tissue was prepared. Briefly, tissue was digested with Collagenase IV (10 units/mL) and DNase I $(10 \mathrm{mg} / \mathrm{mL})$ for 1 hour $30 \mathrm{~min}$ in RPMI supplemented with $5 \%$ fetal bovine serum and HEPES buffer solution at $37^{\circ} \mathrm{C}$. Afterwards, cell suspension was rinsed through a 70 $\mu \mathrm{m}$ mesh and leucocytes were isolated by density gradient centrifugation using Ficoll gradients. For flow cytometry analysis, cells were stained with fluorescence antibodies listed in the online supplementary table 2. Live/dead discrimination was performed with fixable viability dye (BioLegend). Samples were acquired on a FACSAria III (BD) and analyzed with Flowjo software (V.10.6.1)

\section{Irradiation protocol}

A Theratron 780 (MDS Nordion) radiotherapy unit with a Cobalt-60 source was used for $\gamma$-irradiation of OTA, ex vivo cultures of rectal cancer tissue, monocyte-derived macrophages and cancer cell lines. Tissue samples of rectal cancer were minced and cultivated. Petri dishes with cancer tissue were irradiated with $1 \times 2 \mathrm{~Gy}$. After 3 hours of incubation, a single-cell suspension was prepared. OTA and cancer cell lines (HCT116 and DLD-1) were irradiated with $2 \times 2$ Gy or $2 \times 5$ Gy and subsequently cultivated over the course of 24 hours. Monocyte-derived macrophages were irradiated with 2 Gy or 5 Gy. A negative control ( $0 \mathrm{~Gy})$ was always transported to the radiotherapy unit but was not exposed to $\gamma$-irradiation.

\section{Ex vivo phagocytosis assay}

Mononuclear cells isolated of rectal cancer lesions were spun down at $1200 \mathrm{~g}$, for $5 \mathrm{~min}$, at $4^{\circ} \mathrm{C}$. For ex vivo Escherichia coli (E. coli) phagocytosis assay irradiated and non-irradiated leucocytes were resuspended in $100 \mu \mathrm{L}$ pHrodo Red E. coli bioparticles (Thermo Fisher Scientific) as per the manufacturer's instruction. A same set of cells were resuspended in phosphate-buffered saline (PBS) as controls. After 2 hours incubation at $37^{\circ} \mathrm{C}$, 
leucocytes were washed and stained for flow cytometry. TAM $\left(\mathrm{CD} 11 \mathrm{~b}^{+}, \mathrm{CD} 14^{+}, \mathrm{HLA}^{-} \mathrm{DR}^{+}\right.$viable $\mathrm{CD} 45^{+}$cells $)$that were PE high were considered to be phagocytosing. For ex vivo tumor cell phagocytosis assay, TAM were isolated via fluorescence-activated cell sorting (FACS) $\left(\mathrm{CD} 11 \mathrm{~b}^{+}\right.$, $\mathrm{CD}_{14} 4^{+}, \mathrm{HLA}-\mathrm{DR}^{+}$viable $\mathrm{CD} 45^{+}$cells) from healthy colon mucosa or colorectal cancer lesions and incubated overnight with EV isolated from irradiated $(2 \times 2 \mathrm{~Gy})$ and nonirradiated (0 Gy) DLD-1 cells (10,000 EV/TAM). After washing, DLD-1 were labeled with carboxyfluorescein diacetate succinimidyl ester (CFSE, Thermo Fisher, 25 $\mu \mathrm{M})$ and cocultured with TAM at an effector to target cell ratio of 1:10. The proportion of $\mathrm{CFSE}^{+} \mathrm{TAM}$ was assessed by flow cytometry after 4 hours of incubation at $37^{\circ} \mathrm{C}$.

\section{Immunofluorescence and immunohistochemical staining}

Directly and indirectly labeled monoclonal antibodies as listed in online supplementary table 2 and DAPI as a nuclear marker were used. An isotype was used as negative control. In brief, after incubation with the primary antibodies overnight at $4^{\circ} \mathrm{C}$, an appropriate secondary fluorescence-labeled antibody was applied for $30 \mathrm{~min}$ at room temperature, followed by staining of DAPI nuclear marker. For immunohistochemical staining, antibodies were mixed with $2 \%$ bovine serum albumin in PBS and applied overnight to sections in a humid chamber at $4^{\circ} \mathrm{C}$. For visualization of the cells, AEC was used as chromogen. Sections were counter-stained with hematoxylin. For evaluation of staining results, images of whole tissue sections (one section per patient) were acquired using a Z1 Axio Observer microscope equipped with a LD Plan-Neofluar $20 \times / 0.4$ objective (Zeiss). For leucocyte evaluation, the tumor normal interface $(5 \mathrm{~mm}$ on tumor and normal zone) was defined as regions of interests (ROI). For $\gamma \mathrm{H} 2 \mathrm{AX}$ staining, only tumor tissue was selected as ROI. ROI were automatically quantified using TissueFAXS/TissueQUEST image analysis software (TissueGnostics $\mathrm{GmbH}$ ).

\section{Preparation of OTA}

OTA were set up as previously described. ${ }^{35}{ }^{36}$ Briefly, cancer-associated fibroblasts (CAF) were isolated and cultured from fresh samples of colon adenocarcinomas. For the preparation of macrophages, monocytes were isolated using the EasySep Direct Human Monocyte Isolation Kit (Stemcell Technologies) according to the manufacturer's instructions. $2 \times 10^{5} \mathrm{CAF}$ and monocytes per OTA were mixed and pelleted by centrifugation at 250 $\mathrm{g}$ for $10 \mathrm{~min}$. For the collagen gel preparation, all steps were performed on ice. Collagen solutions were prepared by mixing $2 \mathrm{mg} / \mathrm{mL}$ of collagen I (rat tail, $3.48 \mathrm{mg} / \mathrm{mL}$, Becton Dickinson) and the fibroblast/monocyte suspension in Dulbecco's Modified Eagle Medium (DMEM) supplemented with $10 \%$ endothelial cell growth medium MV2 (EGM, Promocell). A total of $300 \mu \mathrm{L}$ each of the collagen-cell suspension were transferred into silicone gel casting devices. After polymerization of the collagen solution, the gels were lifted up on nylon mesh discs and transferred onto metal grids in 6-well plates and cultured at the air-liquid interface in DMEM supplemented with $10 \%$ EGM. For seeding of tumor cells, nylon discs with collagen-cell cylinders were transferred into 24-well plates. Five hundred microlitres of a tumor cell suspension with $2 \times 10^{6}$ cells $/ \mathrm{mL}$ (HCT116 or DLD-1) were added to each well. After 24 hours the tumor cells attached to the surface of the collagen gels and the nylon meshes with the tumor cell colonized collagen-cell cylinders were put back onto the metal grids and incubated for 7 days with media changes every 2 days prior to further experiments. For further assessment, OTA were embedded in Optimal Cutting Temperature media, snap-frozen in liquid nitrogen, and stored at $-80^{\circ} \mathrm{C}$ until processing or fixed and embedded in paraffin.

\section{Macrophage differentiation}

PBMC were obtained by Ficoll-Plaque density gradient centrifugation. PBMC were seeded at a concentration of $5 \times 10^{6}$ /well (6-well plates) in RPMI 1640 medium. Monocytes were isolated using the ability of monocytes to adhere to non-tissue culture treated plastic culture dishes. Attached cells were cultivated in RPMI 1640 medium with Glutamax (Thermo Fisher Scientific) supplemented with $100 \mathrm{ng} / \mathrm{mL}$ macrophage colony stimulating factor (M-CSF, Thermo Fisher Scientific), 10\% fetal bovine serum, $100 \mathrm{U} / \mathrm{mL}$ penicillin, $100 \mathrm{U} / \mathrm{mL}$ streptomycin and $0.25 \mu \mathrm{g} / \mathrm{mL}$ fungizone in a humidified atmosphere at $37^{\circ} \mathrm{C}$. Cells were cultivated for 7 days with two medium changes. To obtain M1 (LPS+IFN- $\gamma$ )-polarized macrophages, cells were stimulated with $100 \mathrm{ng} / \mathrm{mL}$ lipopolysaccharide (LPS) (Sigma Aldrich) and $100 \mathrm{ng} /$ $\mathrm{mL}$ interferon- $\gamma$ (IFN- $\gamma$, Thermo Fisher Scientific) for 48 hours. M2 (IL-4+IL-13)-polarized macrophages were generated using $20 \mathrm{ng} / \mathrm{mL}$ interleukin (IL)-4 (Strathmann) and $20 \mathrm{ng} / \mathrm{mL}$ IL-13 (BioLegend).

\section{EV preparation and characterization}

EV were isolated by differential centrifugation. HCT116 and DLD-1 cells were cultured in McCoy's 5A medium supplemented with $10 \%$ exosome-depleted fetal calf serum. Briefly, cancer cell line culture medium was centrifuged at $300 \mathrm{~g}$ for $10 \mathrm{~min}$ to pellet cells, supernatant was transferred to new falcon tubes and then centrifuged at $2000 \mathrm{~g}$ for $20 \mathrm{~min}$ to pellet dead cells and apoptotic bodies (Rotanta 460RC, Hettich). Supernatant was transferred to the high-speed centrifugation tubes and large $\mathrm{EV}$ were removed by ultracentrifugation at $13,500 \mathrm{~g}$ for 30 min (Sorvall Evolution RC, Thermo Fisher Scientific). After filtration of the supernatant through a $0.22 \mu \mathrm{m}$ syringe filter, small EV were pelleted by ultracentrifugation at 246,836 $\mathrm{g}$ for $90 \mathrm{~min}$ (rotor T-1250), suspended in ice-cold PBS and collected after another ultracentrifugation at $92,500 \mathrm{~g}$ for $90 \mathrm{~min}$ (rotor type 25, Sorvall WX Ultra 100, Thermo Fisher Scientific). The EV pellet was resuspended in cold PBS for further use. EV count was determined using a Nanoparticle tracking analyzer (ZetaView, Particlemetrix). Results were analyzed with ZetaView software. EV were added to macrophages at a 
concentration of $2 \times 10^{9} / 1 \times 10^{6}$ cells. We have submitted all relevant data of our experiments to the EV-TRACK knowledgebase (EV-TRACK ID: EV200065). ${ }^{37}$

\section{Western blot}

Cells were scraped from cell-culture plates, washed in ice-cold PBS and lysed in 1× RIPA buffer $(25 \mathrm{mM}$ TRIS-HCl pH 7.5, $150 \mathrm{mM} \mathrm{NaCl,} 1 \%$ NP-40, $1 \%$ sodium deoxycholate, $0.1 \%$ SDS) containing $1 \times$ Halt protease inhibitor cocktail (Thermo Fisher Scientific). EV suspensions were mixed with $5 \times$ RIPA buffer containing $5 \times$ Halt protease inhibitor cocktail to obtain $1 \times$ concentration. Protein extracts were incubated at $4^{\circ} \mathrm{C}$ for $10 \mathrm{~min}$ and centrifuged at 14,000 g for $15 \mathrm{~min}$. Clear protein extract supernatants were quantified with the BCA Protein Assay Kit (Thermo Fisher Scientific). One to five micrograms of protein were denatured with Laemmli buffer, loaded into each well of a $12 \%$ acrylamide-bisacrylamide (29:1) gel containing $0.1 \%$ SDS and electrophoresed with $12 \mathrm{~mA} /$ gel for 200 Vhours. Proteins were transferred to a polyvinylidene fluoride membrane using the Transblot Turbo and the RTA Ready-to-assemble Transfer Kit (Bio-Rad). After several hours of blocking PVDF membranes were incubated with primary antibodies (online supplementary table 2) at $4^{\circ} \mathrm{C}$ overnight. After washing with TrisBuffered Saline, 0.1\% Tween 20 Detergent, membranes were incubated with the secondary antibody anti-rabbit Immunoglobulin G (IgG) HRP linked antibody (Cell Signaling Technology) or anti-mouse IgG HRP linked antibody (Cell Signaling Technology) at room temperature for 1 hour. Detection was done with Clarity or Clarity Max Western ECL Substrate (Bio-Rad). Protein band intensities were quantified with ImageQuant TL 7.0 (GE Healthcare).

\section{Electron microscopy}

After mounting Cu 200 mesh R2/2 holy carbon grids (Quantifoil) with a tweezer into a Leica GP (Leica Microsystems) grid plunger $4 \mu \mathrm{L}$ of EV sample solution were applied to grid's front side and blotted for 2-4 s. Grids were plunge frozen into liquid ethane for instant vitrification and transferred to a Glacios cryotransmission microscope (Thermo Fisher Scientific) equipped with a X-FEG. Images were recorded in lowdose mode using the SerialEM software (Mastronarde, 2005 ) with a Falcon3 direct electron detector at magnifications of 5300, 36,000 and 150,000 with pixel sizes of 27.5, 4.1 and $0.98 \AA$, respectively.

\section{Statistical analysis}

Statistical analysis was performed using GraphPad Prism 8 (GraphPad Software). Statistical significance was determined by Student's t-test when comparing two groups. The two-way analysis of variance followed by Tukey's multiple comparison test was used when comparing three or more groups. Significance was set at a $\mathrm{p}$ value of less than 0.05 .
RESULTS

\section{TAM in rectal cancer polarize towards M1-like phenotype upon irradiation}

We first investigated the effect of irradiation on human TAM in a primary ex vivo culture of rectal cancer specimen. For this purpose, minced tumor tissue was irradiated with 2 Gy and subsequently cultivated for 3 hours before leucocyte isolation (figure 1A). The gating strategy for macrophages isolated from viable $\mathrm{CD} 45^{+}$mononuclear cells of human rectal cancer is shown in figure 1B. TAM (as defined by $\mathrm{CD}_{14} / \mathrm{CD} 11 \mathrm{~b}^{+} / \mathrm{CD} 8^{+} / \mathrm{HLA}^{-D R^{+}}$) accounted for over $8 \%$ of all viable $\mathrm{CD} 45^{+}$leucocytes in rectal cancer (figure 1C) with over 1000 cells per gram of tissue (figure 1D). There was no significant difference in percentage or absolute numbers of TAM in non-irradiated versus corresponding ex vivo irradiated tissue samples (figure 1C,D). We then assessed the phenotype of treatment naïve and ex vivo irradiated TAM using flow cytometry. In naive rectal cancer lesions TAM were characterized by high expression of CD206, CD163 and CD64 and low levels of the chemokine receptor CCR7 indicating that the M2-like macrophage phenotype was present in untreated rectal cancer (figure 1E). This was also reflected in their cytokine pattern as more TAM in untreated rectal cancer samples produced IL-10, IL-13 and IL-4, while few interferon- $\gamma$ (IFN- $\gamma$ )- and tumor necrosis factor alpha (TNF- $\alpha$ )-producing TAM were found in untreated samples. In contrast, ex vivo application of 2 Gy $\gamma$-irradiation to primary rectal cancer leucocytes resulted in a reduced presence of $\mathrm{CD} 163^{+} \mathrm{TAM}$. This phenotype correlated with enhanced levels of TNF- $\alpha^{+}$and iNOS ${ }^{+}$TAM as well as diminished detection of $\mathrm{IL}_{-}-10^{+}$and IL-13 ${ }^{+}$TAM. Hence, low-dose irradiation of rectal cancer tissue can polarize TAM towards a pro-inflammatory M1-like phenotype and may therefore directly contribute to antitumor activity by TNF- $\alpha$ and iNOS production.

\section{Low-dose irradiation reduces PD-1 expression and enhances phagocytosis in TAM to $E$. coli}

To further assess the distinct functional phenotype of TAM on irradiation we investigated the ability of TAM to phagocyte as an aspect of direct effector function and activation. To model the phagocytic behavior of irradiated TAM, we incubated leucocytes derived from irradiated ex vivo tumor culture with $\mathrm{pH}$ sensitive PE-labeled E. coli particles. In the phagosome, the fluorescence of $E$. coli particles increases as demonstrated in a representative example (figure 2A). Phagocytosis by TAM was significantly elevated upon irradiation with $2 \mathrm{~Gy}$ (figure 2B), demonstrating that the acquired shift towards M1 polarization due to irradiation was also functionally relevant. As PD-1 was previously shown to inhibit phagocytosis, ${ }^{38}$ we next determined PD-1 expression on irradiated ex vivo tumor culture-derived TAM. We found variable PD-1 expression on TAM in non-irradiated rectal cancer and observed a significant decrease of PD-1 on TAM derived from irradiated cultures (figure 2C). These 
changes, induced by irradiation, can be instrumental for phagocytic activity of TAM.

\section{Irradiation promotes antigen presentation and cytokines associated with Th1 response}

One of the hallmarks of $\mathrm{M} 1$ polarization of macrophages is the acquisition of antigen-presenting features leading to efficient Th1 response. ${ }^{17}$ As a first step to determine whether irradiation may result in improved capability of TAM to initiate immune responses, we analyzed the expression of CD86 on TAM derived from irradiated ex vivo tumor cultures. Irradiation correlated with a significant increase of CD86 on the cell surface of TAM as compared with TAM derived from non-irradiated naïve cultures (figure 2D). We next investigated HLA-DR on non-irradiated TAM versus TAM irradiated with 2 Gy. We observed HLA-DR low-expressing TAM and highexpressing TAM clearly dividing them into two groups (figure 2E). In non-irradiated samples more than $60 \%$ of TAM expressed high levels of HLA-DR, while irradiation significantly increased the fraction of HLA-DR ${ }^{\text {high }}$ TAM to over $80 \%$. (figure $2 \mathrm{~F}$ ). We next investigated whether irradiation can induce the expression of IL-12 p70 and IL-23 p19 as markers for the initiation of adaptive immune responses. Whereas IL-23 p19 showed a tendency to be produced by TAM on irradiation, IL-12 p70 was significantly induced in irradiated tumor tissue compared with treatment naïve samples (figure 2G). Together these results suggest that low-dose irradiation influences TAM polarization in rectal cancers by equipping the cells with an HLA-DR ${ }^{\text {hi }}$ IL-12 ${ }^{\text {hi }}$-IL-23 ${ }^{\text {hi }}$ cytokine profile. This observation emphasizes that irradiated TAM have a higher probability to participate in antitumor immune responses directly by phagocytosis and cytokine secretion as well as indirectly by exhibiting a broad armamentarium that potentially activates $\mathrm{T}$ cells as main players of antitumor adaptive immunity.

\section{Short-course irradiation of patients with rectal cancer increases the M1/M2 ratio of TAM}

To corroborate our ex vivo data with the in vivo situation on short-course irradiation, we examined TAM polarization and function in rectal cancer patients treated by a routinely applied radiotherapy protocol. We made use of a cohort of patients in clinical stage T3 rectal cancer who received neoadjuvant hyperfractionated short-course radiotherapy (two times 2.5 Gy per day) over the course of 5 days (figure 3A). Surgery was performed 2-5 days after radiotherapy in these patients. As a control, we used surgical specimen from treatment naïve clinical T3 rectal cancer patients. Importantly, the indication for radiotherapy was not correlated with a more severe tumor progression compared with the treatment naïve cohort

A

B
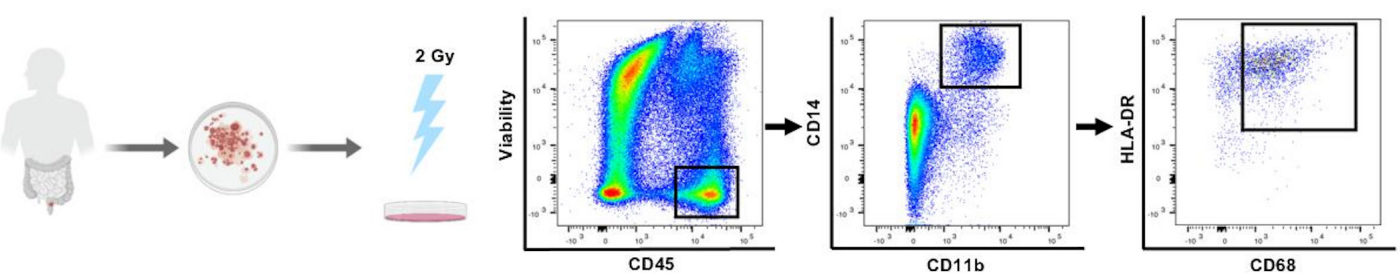

C

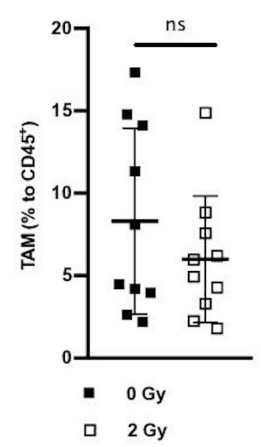

D

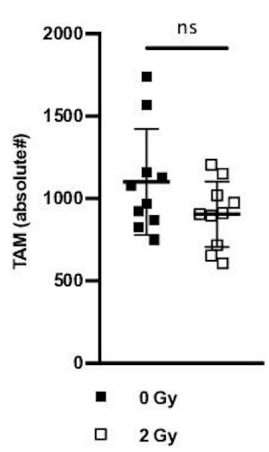

E

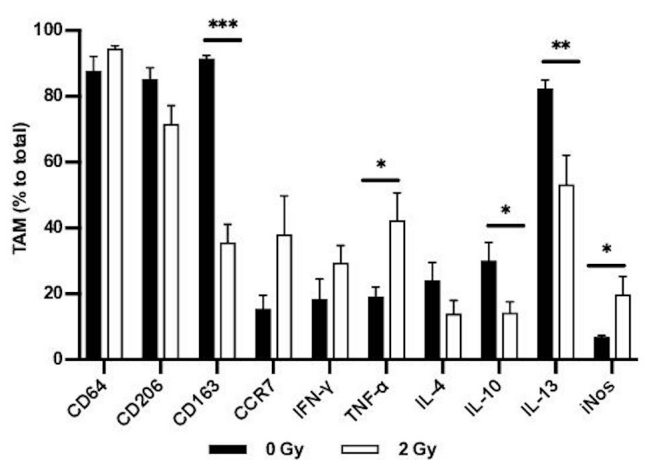

Figure 1 Ex vivo $\gamma$-irradiation induces polarization of tumor-associated macrophages. (A) Tissue samples of naïve rectal cancer were minced and irradiated. After incubation a single-cell suspension of cancer tissue was prepared. (B) Representative example of the gating strategy for macrophages isolated from viable CD $45^{+}$mononuclear cells of human rectal cancer. (C) Percentage of macrophages compared to total of viable $\mathrm{CD}_{4} 5^{+}$cells in non-irradiated and ex vivo irradiated rectal cancer lesions assessed by flow cytometry and presented as mean $\pm S D, n=10$. (D) Mean numbers of macrophages in rectal cancer per gram in non-irradiated and ex vivo irradiated rectal cancer, presented as mean $\pm S D, n=10$. (E) Expression of intracellular and extracellular markers in macrophages assessed by flow cytometry. Bars presented as mean percentage of indicated markers $\pm S D$ of non-irradiated and ex vivo irradiated macrophages, $n=10 .{ }^{*} P<0.05,{ }^{* *} p<0.001,{ }^{* \star *} p<0.0001$, by two-tailed paired Student's t-test. Gy, Gray; TAM, tumor-associated macrophages; IFN- $\gamma$, interferon- $\gamma$; TNF- $\alpha$, tumor necrosis factor- $\alpha$; IL, interleukin; iNOS, inducible nitric oxide synthase. 
A

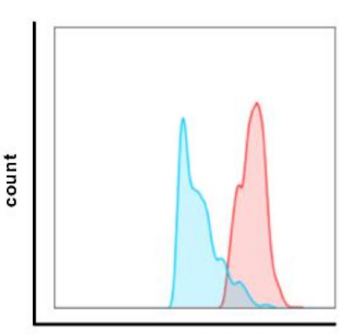

pHrodo $\mathrm{PE}^{+}$E.coli
B

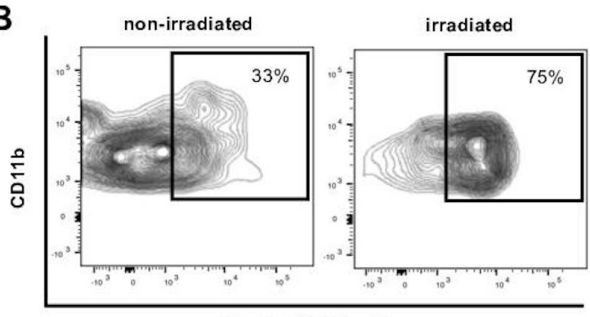

pHrodo $\mathrm{PE}^{+}$E.coli

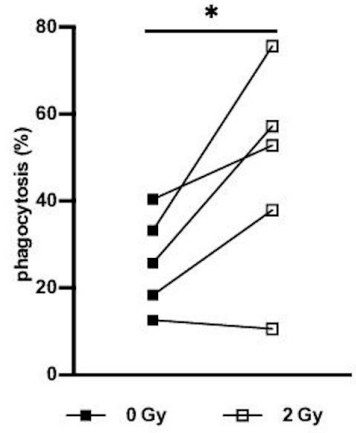

D
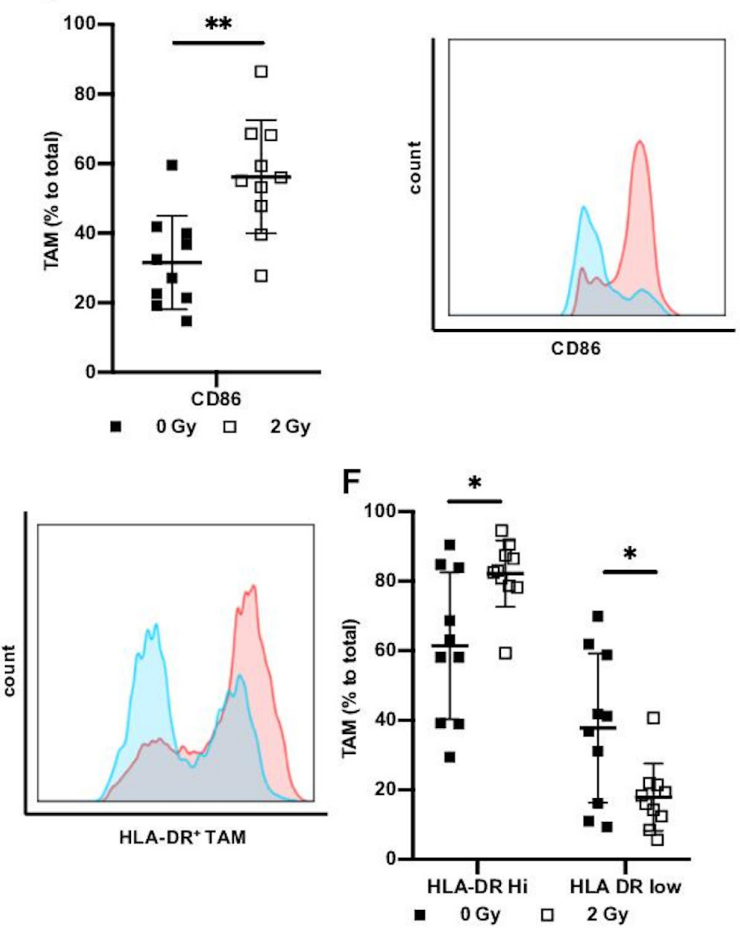

G
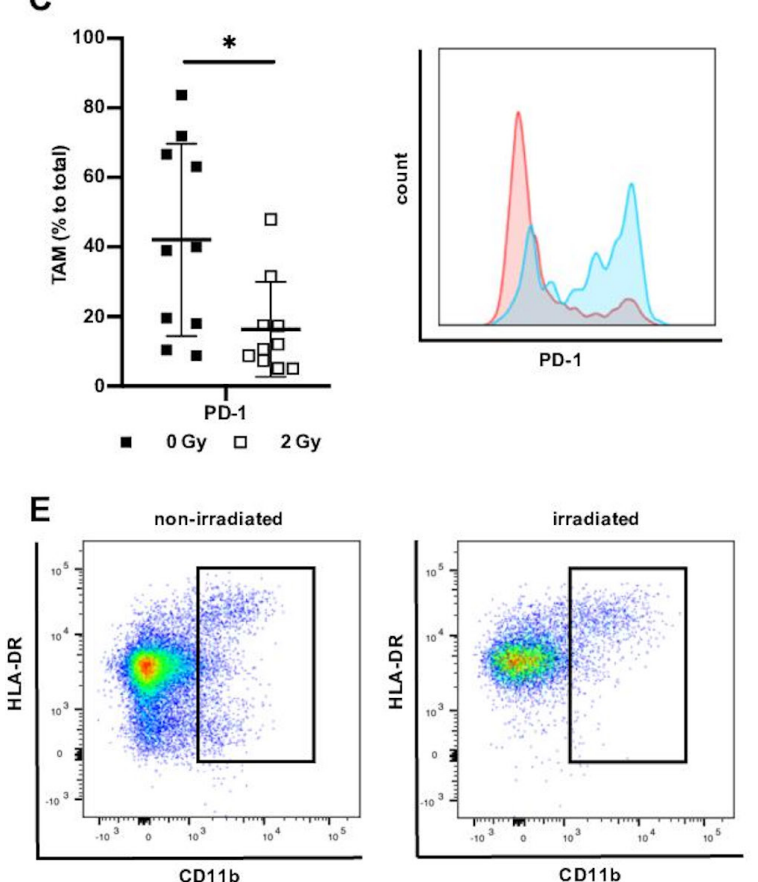

Figure 2 Irradiation increases phagocytosis and marker associated with antigen presentation and Th1 response. (A) Representative histogram and flow cytometry plots indicating difference in PE fluorescence of non-irradiated (blue) versus irradiated (red) TAM in ex vivo phagocytosis assay. Total phagocytosis was analyzed by first gating on TAM, and then gating on $\mathrm{PE}^{+}$cells. (B) Analysis of TAM phagocytosis of pHrodo E. coli particles. Data presented as percentage of phagocytosis of nonirradiated TAM and corresponding irradiated TAM (2 Gy), $n=5$. (C) Percentage of TAM positive for PD-1 non-irradiated versus ex vivo irradiated and representative histogram (non-irradiated/blue vs irradiated/red). Data presented as mean $\pm S D, n=10$. (D) Percentage of expression of CD86 in non-irradiated versus ex vivo irradiated TAM and representative histogram (non-irradiated/ blue vs irradiated/red). Data presented as mean $\pm S D$. $n=10$. (E) Representative plots, histogram and (F) expression of HLA-DR on TAM of non-irradiated and ex vivo irradiated rectal cancer. Data given as mean $\pm S D, n=10$. (G) Expression of IL-12 p70 and IL-23 p19. Data presented as mean percentage $\pm S D$ of total TAM, $n=10$. Representative example of IL-12 p70 and IL-23 p19 expression on TAM. ${ }^{*} \mathrm{P}<0.05,{ }^{* *} \mathrm{p}<0.001$, by two-tailed paired Student's t-test. Th1, Thelper type 1; Gy, Gray; TAM, tumorassociated macrophages; IL, interleukin. 
A
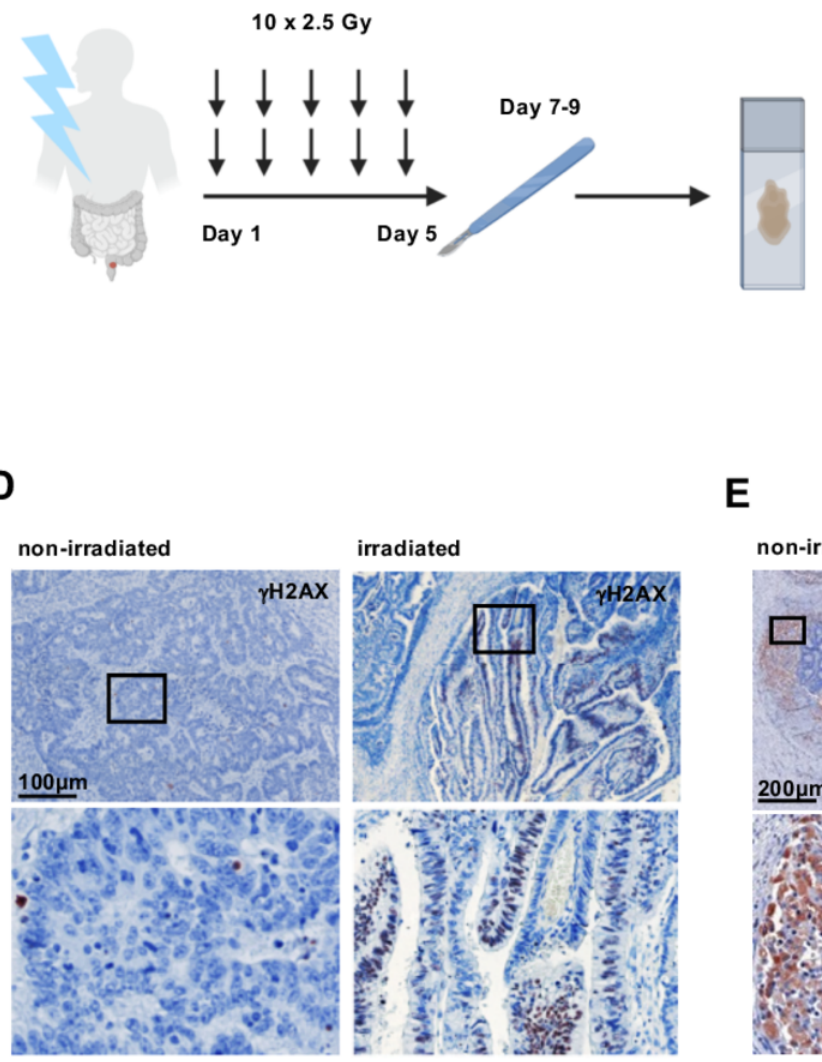

G
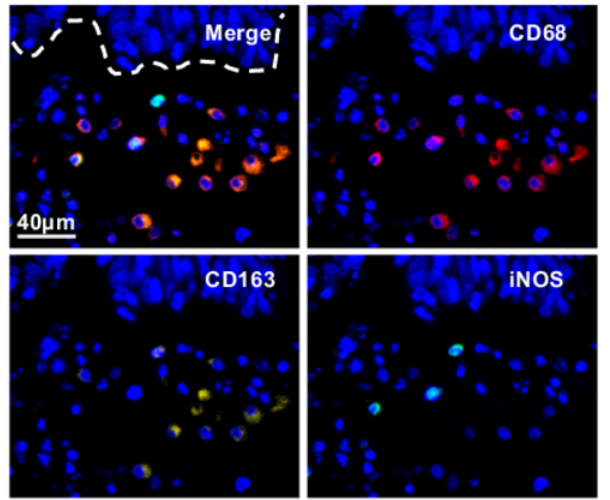

B

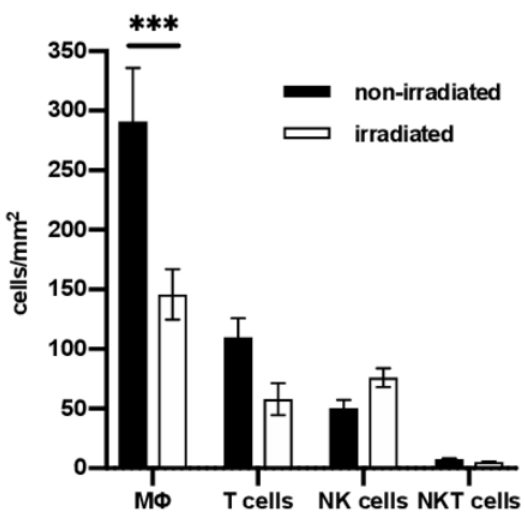

E

C

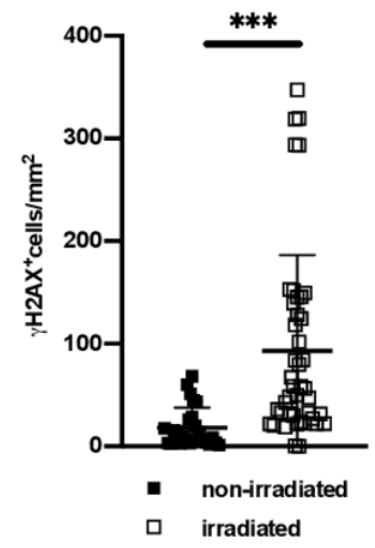

F

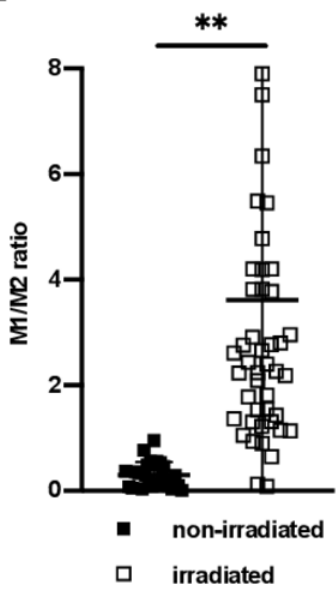

H

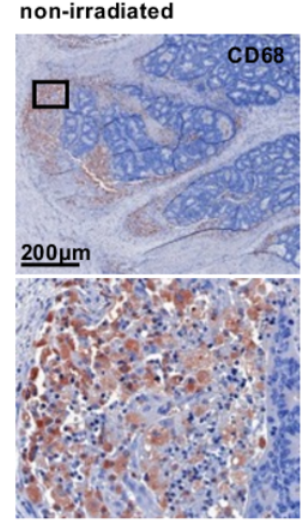

irradiated

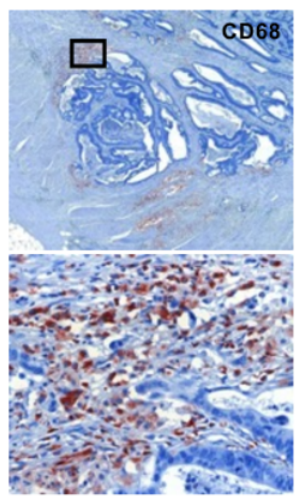

I

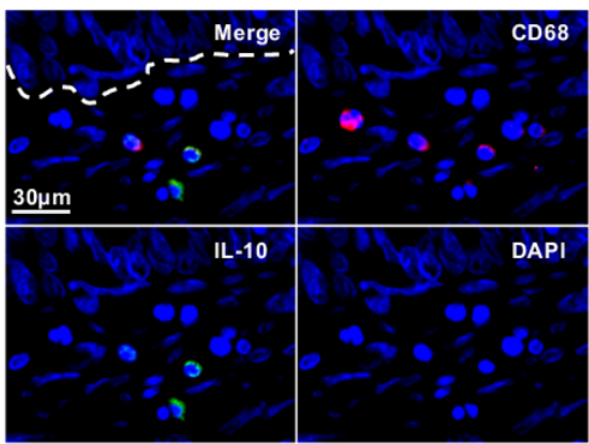

- non-irradiated

$\square \quad$ irradiated

Figure 3 Short-course irradiation in patients modulates the immune infiltrate with induction of macrophage polarization. (A) Irradiation protocol of patients with neoadjuvant hyperfractionated $(2 \times 2.5$ Gy per day over the course of five days) radiotherapy for clinical T3 rectal cancer. Surgery was performed the following week. (B) Quantitative in situ assessment of infiltrating macrophages $\left(\mathrm{CD}^{+} 8^{+}\right)$, T cells $\left(\mathrm{CD} 3^{+} \mathrm{CD} 56-\right)$, NK cells $\left(\mathrm{CD} 56^{+} \mathrm{CD} 3-\right)$ and NKT cells $\left(\mathrm{CD} 56^{+} \mathrm{CD}^{+}\right)$in non-irradiated $(\mathrm{n}=25)$ and irradiated rectal cancer $(n=45)$ assessed by multicolor immunofluorescence staining. Data are given as absolute numbers of positive cells per $\mathrm{mm}^{2}{ }_{ \pm} \mathrm{SD}$. (C) Analysis of immunohistochemical staining for $\gamma \mathrm{H} 2 \mathrm{AX}$ as irradiation response in non-irradiated $(n=25)$ and irradiated tissue sections. Data are given as mean \pm SD. (D) Representative examples of immunohistochemical staining for $\gamma \mathrm{H} 2 \mathrm{AX}$. Images below are magnified 200x. (E) Representative immunohistochemical staining of $\mathrm{CD}^{2} 8^{+}$cells in non-irradiated $(n=25)$ and irradiated tissue sections $(n=45)$. Images below are magnified 200x. (F) Representative example of immunofluorescence multicolor staining of $\mathrm{CD}^{+} 8^{+}$macrophages (PE), M1(iNOS FITC), M2 (CD163 APC). (G) Quantitative in situ analysis of immunofluorescence staining of ratio of $\mathrm{NOS}^{+}(\mathrm{M} 1)$ to $\mathrm{CD} 163^{+}$(M2) TAMs. CD68 ${ }^{+}$macrophages presented as M1/ M2 in non-irradiated $(n=25)$ compared to irradiated sections $(n=45)$. Data are given as mean $\pm S D$. $(H)$ Percentage of IL-10 $0^{+}$cells to total $\mathrm{CD} 8^{+}$cells. Data are presented as mean $\pm \mathrm{SD}$. (I) Representative image of multicolor immunofluorescence staining of IL-10 in macrophages (CD68 PE/IL-10 FITC) of irradiated rectal cancer. ${ }^{* \star} \mathrm{P}<0.001,{ }^{* \star *} \mathrm{p}<0.0001$ by two-tailed unpaired Student's t-test. Gy, Gray; iNOS, inducible nitric oxide synthase; TAM, tumor-associated macrophages; IL, interleukin. 
since the stage in the TNM Classification of Malignant Tumors and cancer differentiation of the two cohorts were comparable (online supplementary table 1).

To assess the composition of the leucocytic infiltrate and the impact of radiotherapy, we evaluated the distribution of macrophages, T cells, NK cells and NKT cells via immunofluorescence staining and automated image analysis. Irradiated tumor sections showed significantly less infiltration of $\mathrm{CD} 68^{+}$cells, which correlated with a tendency for a decrease of $\mathrm{CD}^{+} \mathrm{T}$ cells, while the amount of NK cells $\left(\mathrm{CD} 56^{+}, \mathrm{CD} 3-\right)$ or $\mathrm{NKT}\left(\mathrm{CD} 56^{+}, \mathrm{CD}^{+}\right)$ cells did not show significant differences (figure 3B). Immunostaining of phosphorylated $\gamma \mathrm{H} 2 \mathrm{AX}$ was used to confirm radiotherapy-induced DNA damage in analyzed tumor specimen. Irradiated tumors revealed a significantly higher amount of $\gamma \mathrm{H} 2 \mathrm{AX}$ positive cells than nonirradiated tissue (figure 3C). $\gamma \mathrm{H} 2 \mathrm{AX}$ foci were primarily located in the nuclei of tumor cells rather than in the cells of the tumor infiltrating microenvironment (figure 3D). In both patient cohorts, $\mathrm{CD} 68^{+}$cells accumulated in regions surrounding tumor cell clusters (figure $3 \mathrm{E}$ ).

To evaluate the in vivo effect of irradiation on macrophage polarization and to correlate results with ex vivo irradiated tumor specimens, we determined the ratio of M1-like TAM to M2-like TAM by staining for iNOS and $\mathrm{CD} 163$ in $\mathrm{CD}^{+} 8^{+}$cells. Irradiation was associated with higher numbers of iNOS-expressing TAM, while CD163 ${ }^{+}$ TAM were drastically reduced resulting in a significant increase in the M1/M2 ratio (figure $3 \mathrm{~F}, \mathrm{G}$ ). Similar to the ex vivo cultures we observed a sixfold decrease of IL- $10^{+}$ TAM in tumors from irradiated patients as compared with treatment naive tumors (figure $3 \mathrm{H}, \mathrm{I}$ ). These data are corroborating hallmarks of our ex vivo irradiation protocols with macrophages becoming active players within the tumor microenvironment upon $\gamma$-irradiation.

\section{Irradiation of organotypic cultures promote macrophage activation towards an M1-like phenotype}

To be able to further dissect the irradiation-induced findings in patients, tissue sections and ex vivo cultures, we used organotypic cultures, which were established with colorectal cancer cell lines (HCT116 or DLD-1), primary CAF and peripheral blood-derived macrophages (online supplementary figure A) in collagen I gels. In contrast to primary cultures, OTA allowed culture periods of up to 5 days. To mimic the clinical protocol of short-course irradiation, OTA containing either HCT116 or DLD-1 were exposed to irradiation with two times 2 Gy or two times 5 Gy over the course of 24 hours, compared with non-irradiated controls (figure 4A,B). Frozen tissue sections of OTA were assessed for macrophage marker using immunostaining and automated image analysis. The number of macrophages in OTA was comparable and not significantly different among the distinct conditions (online supplementary figure B). Nonirradiated (0 Gy) OTA harbored macrophages resembling

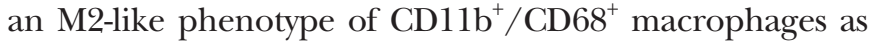
indicated by high expression of CD163 (figure 4C,D), low expression of CCR7 (figure 4E) and modest expression of IL-10 (figure 4F,G). Upon irradiation of OTA, CD163 and IL-10 were reduced, whereas the expression of the pro-inflammatory marker CCR7 was elevated. Thus, the marker profile of OTA correlated with those of primary ex vivo tumor cultures and surgical specimen following neoadjuvant irradiation. These observations support the notion that OTA can be exploited to investigate patient-relevant pathways.

To investigate if irradiation has direct effects on the phenotype of macrophages, we differentiated monocytederived macrophages towards M1-like phenotype and M2-like phenotype and applied 2 or 5 Gy of $\gamma$-irradiation to the cells. In M2-differentiated macrophages, no significant difference was observed between irradiated and non-irradiated cells (online supplementary figure C). For M1-polarized macrophages, we observed a significant increase in the expression of CCR7 and CD206 after $\gamma$-irradiation (online supplementary figure $\mathrm{D}$ ). The expression of other markers was not altered. We therefore conclude that the direct effect of macrophage irradiation is not the main contributor to the observed changes in phenotype and that other factors must be at play.

\section{High mobility group box 1 (HMGB1) release upon irradiation in organotypic cultures}

Paraffin-embedded tissue sections of OTA were immunostained for phosphorylated $\gamma \mathrm{H} 2 \mathrm{AX}$ to confirm irradiationinduced DNA damage. Quantitative automated image analysis was performed for intracellular foci of $\gamma \mathrm{H} 2 \mathrm{AX}$ in OTA sections (figure 5A). Quantification demonstrated a dose dependent induction of $\gamma \mathrm{H} 2 \mathrm{AX}$ (figure 5B). To confirm a potential role for immune cells in tumor microenvironment on irradiation, we next evaluated the induction of HMGB1 in irradiated OTA serving as a surrogate marker for ICD. HMGB1 was primarily expressed in the nuclei and to lower frequency in the cytoplasm of nearly all cell types in treatment naïve OTA (0 Gy); (figure 5C). However, in irradiated OTA $(2 \times 5 \mathrm{~Gy})$, we observed a significant induction of HMGB1-specific staining in both, the nucleus and cytoplasm (figure 5C). This pattern suggests an induction of ICD, as a potential prerequisite of cancer cells and macrophages crosstalk.

\section{Macrophage polarization can be mediated by EV derived from irradiated cancer cells}

To unravel underlying mechanisms for TAM polarization, we aimed to define the role of EV in irradiated cancer tissue. We isolated EV from irradiated or non-irradiated DLD-1 and HCT116 cells using ultracentrifugation. EV were characterized by their size in nanoparticle tracking analysis (figure 6A), their distinct bilipid layer in electron microscopy (figure 6B) and expression profile in Western blots (figure 6C). EV stained positive in Western blot analysis for characteristic EV marker CD9, CD81, TSG101 and negative for calreticulin. Interestingly, irradiation-induced HMGB1 in EV derived from DLD-1 but not HCT116 cells. We then polarized peripheral blood monocytes-derived macrophages towards either the M1 or M2 phenotype 
A

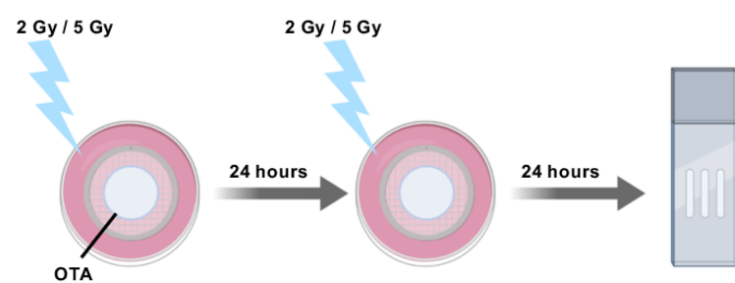

B

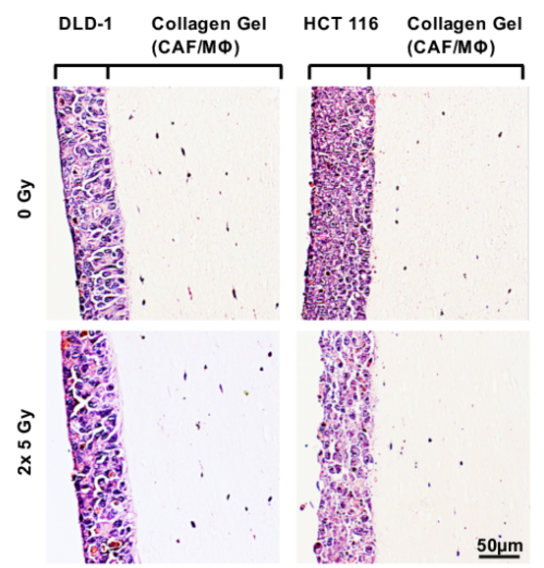

D
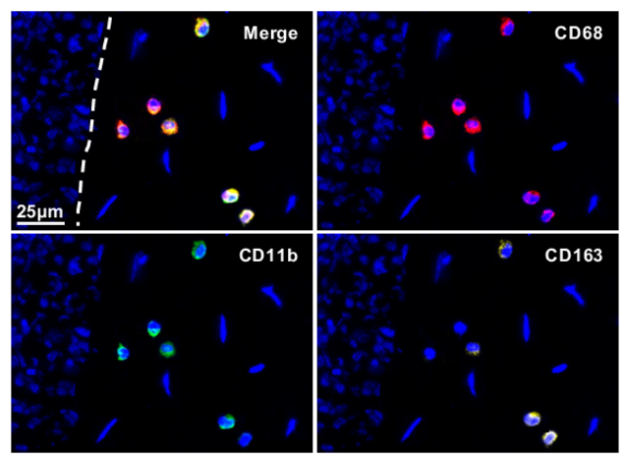

F
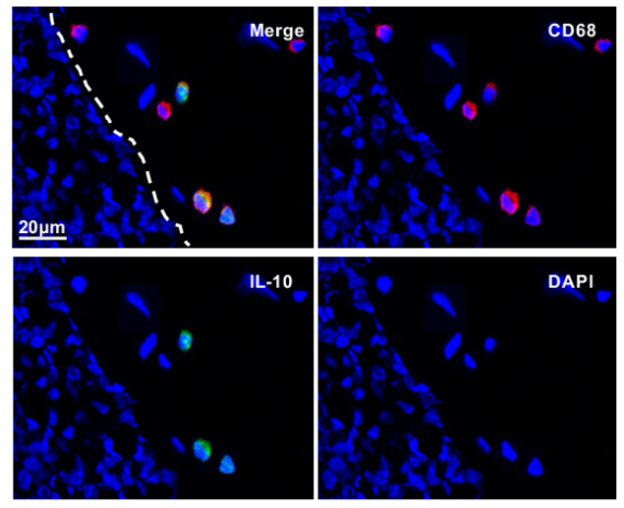

C

CD163

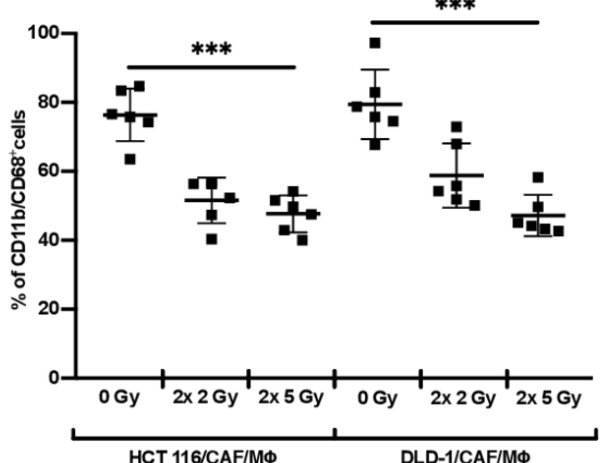

E

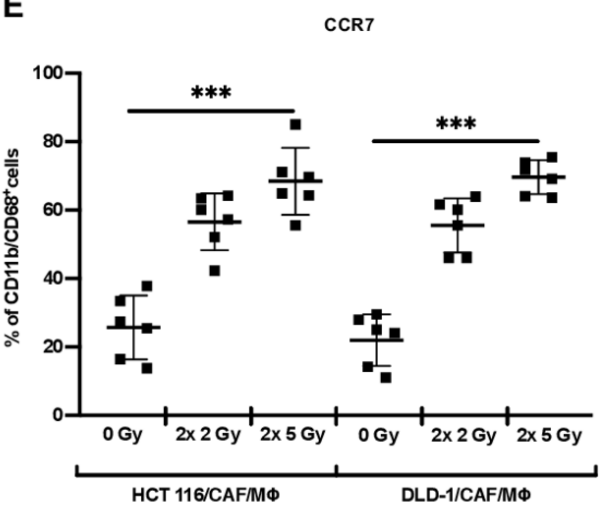

G

IL-10

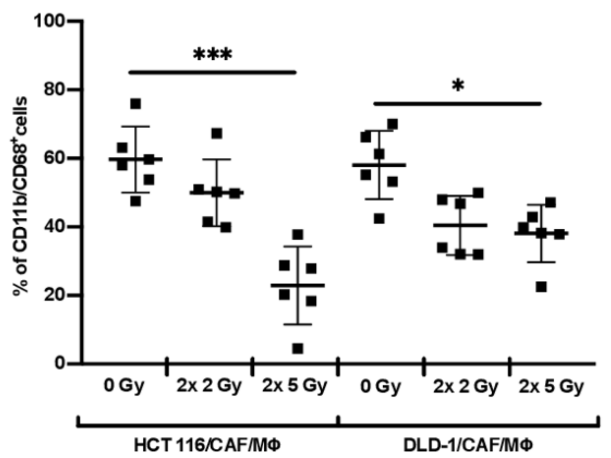

Figure 4 Irradiation of organotypic assays promotes macrophage activation. (A) Organotypic assays (OTA) were irradiated for two times either with 2 Gy or 5 Gy. (B) Histological overview (H\&E staining) of tissue sections of organotypic assays after $\gamma$-irradiation and immunofluorescence staining. The human colorectal cancer cell line (DLD-1, HCT116) with cancer-associated

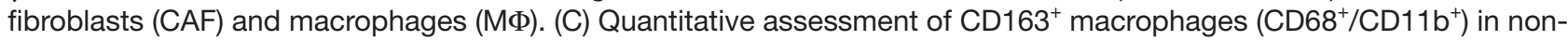
irradiated (0 Gy) and irradiated (2×2 Gy, 2×5 Gy) organotypic cultures. (D) Representative example of macrophages (CD68 PE/ CD11b FITC/CD163 APC) in organotypic assays. (E) Quantitative analysis of CCR7 $7^{+}$macrophages $\left(\mathrm{CD} 68^{+} / \mathrm{CD} 11 \mathrm{~b}^{+}\right)$in nonirradiated (0 Gy) and irradiated (2×2 Gy, 2×5 Gy) organotypic cultures. (F) Representative immunofluorescence staining of organotypic cultures (CD68 PE/IL-10 FITC). (G) Quantitative analysis of $\mathrm{IL}-10^{+}$macrophages $\left(\mathrm{CD} 68^{+} / \mathrm{CD} 11 \mathrm{~b}^{+}\right)$in non-irradiated (0 Gy) and irradiated ( $2 \times 2$ Gy, $2 \times 5$ Gy) organotypic assays. Data are given as percentage of IL- $10^{+}$macrophages $\left(\mathrm{CD}^{2} 8^{+} /\right.$ $\left.\mathrm{CD} 11 b^{+}\right) \pm S D(n=6) .{ }^{*} P<0.05,{ }^{* \star *} p<0.0001$ by one-way analysis of variance followed by Tukey's multiple comparisons tests. Gy, Gray. 

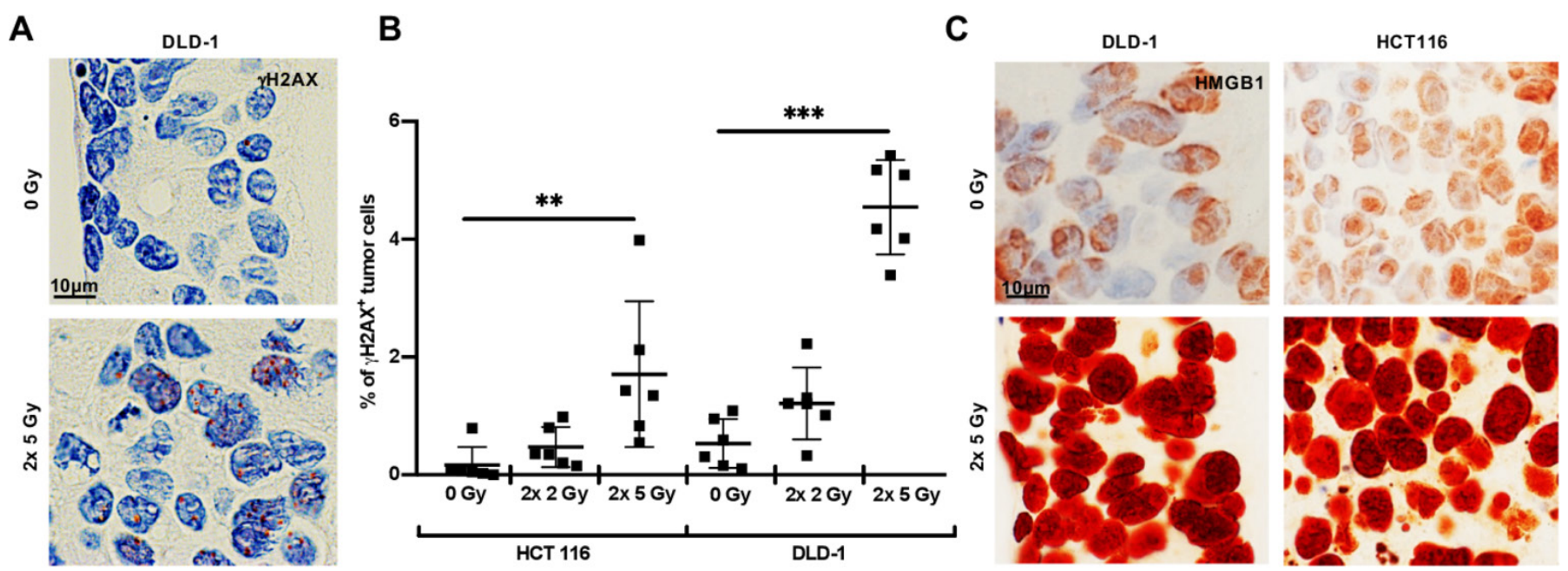

Figure 5 Irradiation evokes marker of immunogenic cell death in organotypic models. (A) Representative examples of intranuclear immunohistochemical staining for $\gamma \mathrm{H} 2 \mathrm{AX}$ as irradiation response in organotypic cultures 0 Gy and 2×5 Gy. (B) Quantitative in situ assessment of $\gamma \mathrm{H} 2 \mathrm{AX}$ non-irradiated ( $0 \mathrm{~Gy}$ ) and irradiated (2×2 Gy; $2 \times 5$ Gy) organotypic cultures of HCT116 or DLD-1. Data are given as percentage of tumor cells positive for $\gamma H 2 A X \pm S D, n=6$. (C) Representative examples of immunohistochemical staining of HMGB1 in organotypic cultures of non-irradiated (0 Gy) and irradiated (2×5 Gy) in DLD-1 and HCT116. ${ }^{* \star} \mathrm{P}<0.001,{ }^{* \star *} \mathrm{p}<0.0001$, by two-way analysis of variance followed by Tukey's multiple comparisons tests. Gy, Gray; HMGB1, high mobility group box 1 .

using LPS+IFN- $\gamma$ or IL-4+IL-13, respectively, resulting in clearly distinct phenotypes (figure 6D). We cocultured these macrophages with EV of irradiated DLD-1 and nonirradiated DLD-1 for 48 hours. Exposure of M2-polarized macrophages to EV derived from irradiated DLD-1 cells led to a significant increase in macrophages expressing activation markers such as CCR7, CD64 and CD86 as well as pro-inflammatory cytokines such as TNF- $\alpha$ and IL-12 p70. Correspondingly, production of IL-10 was abolished under these conditions (figure 6E). In contrast, M1-polarized TAM retained their phenotype, with the exception of an increased expression of CD206 (online supplementary figure E). Hence we concluded that EV released of irradiated DLD-1 cells contain factors leading to a shift from M2 polarization towards the M1 phenotype. A cancer cell phagocytosis experiment was performed with TAM isolated of healthy colon mucosa and colorectal cancer tissue. TAM were pretreated overnight with $\mathrm{EV}$ derived from non-irradiated/irradiated DLD-1 cells. CFSE labeled DLD-1 cancer cell line were then added. Phagocytosis was evaluated with flow cytometry as the percentage of CFSE ${ }^{+}$ TAM. However, no significant differences in the ability to phagocyte were observed.

In summary, our findings highlight the importance of $\mathrm{EV}$ in the crosstalk of tumor cells and TAM upon irradiation, potentially leading to an increased inflammatory response of macrophages in cancer lesions. However, the exact pathways involved as well as the contribution of HMGB1 still needs to be elucidated.

\section{DISCUSSION}

Here, we demonstrate that short-course irradiation applied to rectal cancer patients as part of routine therapy induces a change in the TAM subtype from the M2-like phenotype to the M1-like phenotype. This clinical observation could be modeled by ex vivo stimulation of primary tumor cultures and OTA showing similar effects of irradiation on macrophage function.

We confirmed that colorectal cancer lesions harbor a great number of macrophages that are associated with an immunosuppressive marker profile and decreased expression of several pro-inflammatory cytokines in line with previous reports. ${ }^{3940}$ Our ex vivo experiments demonstrate that lowdose irradiation induced elevated numbers of iNOS- and TNF- $\alpha$-expressing TAM secreting Th1-associated cytokines. The observation correlated with reduced numbers of TAM that expressed $\mathrm{CD} 163^{+}, \mathrm{IL}_{-}-13^{+}$and IL- $10^{+}$(figure 1). This pattern correlated with an increased capacity of phagocytosis in TAM after the application of $\gamma$-irradiation (figure 2). Pinto et al observed that moderate doses of irradiation $(5 \times 2$ Gy) facilitated an increase of HLA-DR and CD86 as well as a decrease of IL-10 in irradiated macrophages cultured form peripheral blood of healthy individuals, whereas other markers were not altered. ${ }^{41}$ In line with these findings, irradiation of murine breast cancer ${ }^{24}$ and prostate cancer ${ }^{25}$ led to an induction of iNOS in macrophages and thus induced a pro-inflammatory phenotype in those cells. We show that the polarization of TAM is a relevant feature in tumor samples of rectal cancer patients after neoadjuvant radiotherapy (figure 3). Importantly, induced changes lasted not only a few hours after irradiation but persisted in case of surgical removed resections at least for $2-5$ days. These findings suggest that irradiation gives rise to a significant repolarization of macrophages suggesting TAM to be direct effector cells in cancer lesions. The clinical cohort of rectal cancer patients used in this study allowed to analyze whole tumor sections as the tumors were surgically resected shortly after the radiotherapy (figure 3). This is crucial 
A

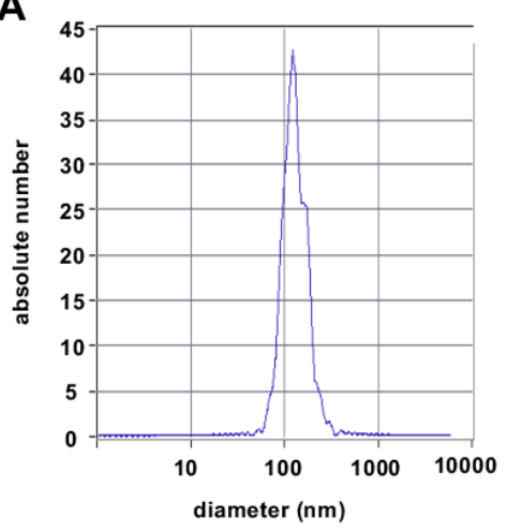

D

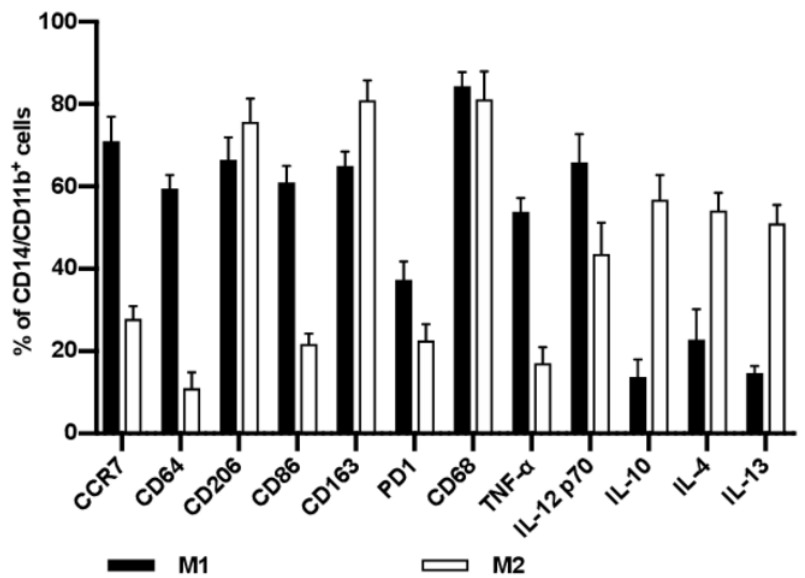

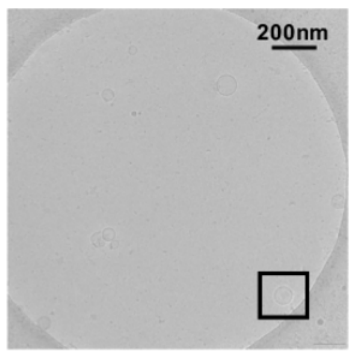

C

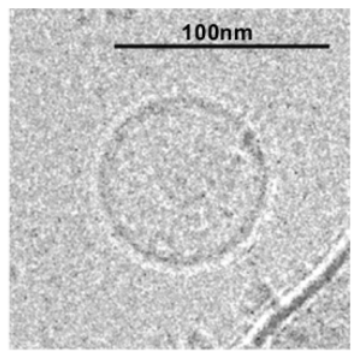

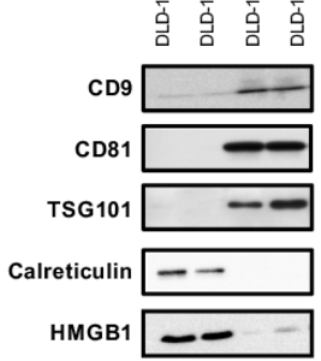

$\mathbf{E}$
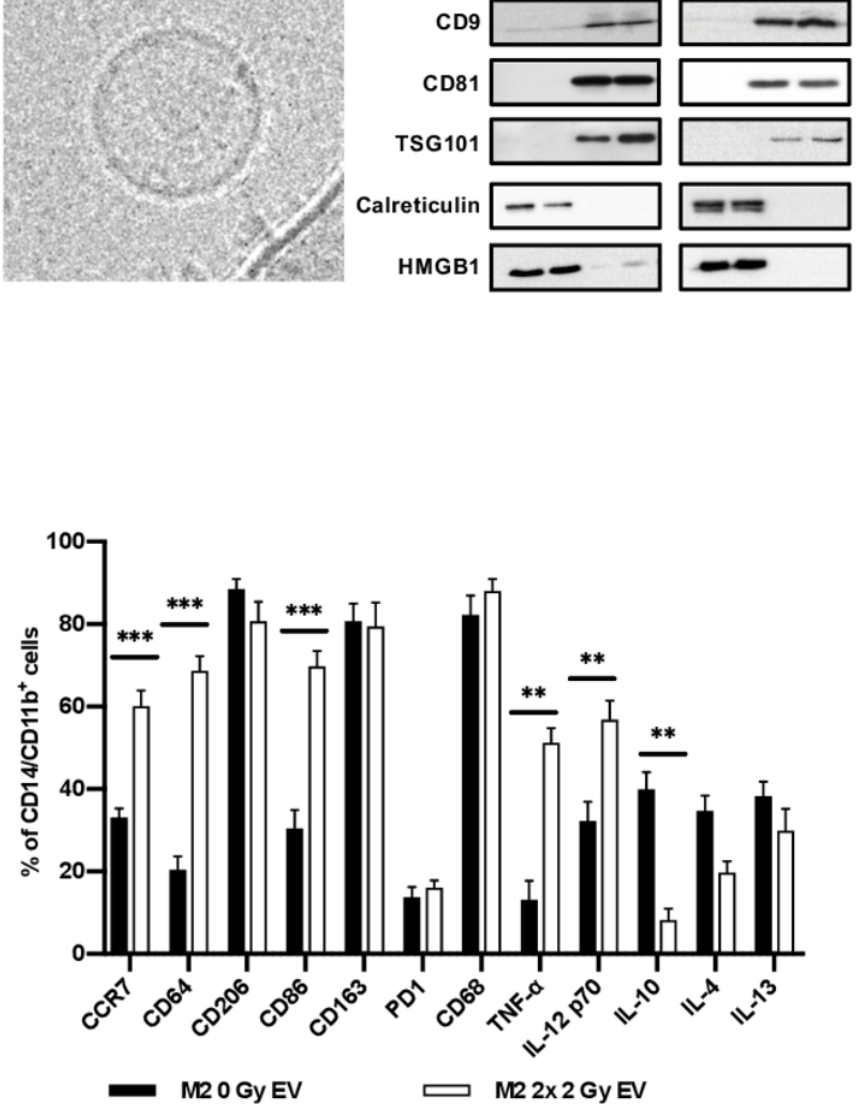

$\mathbf{F}$
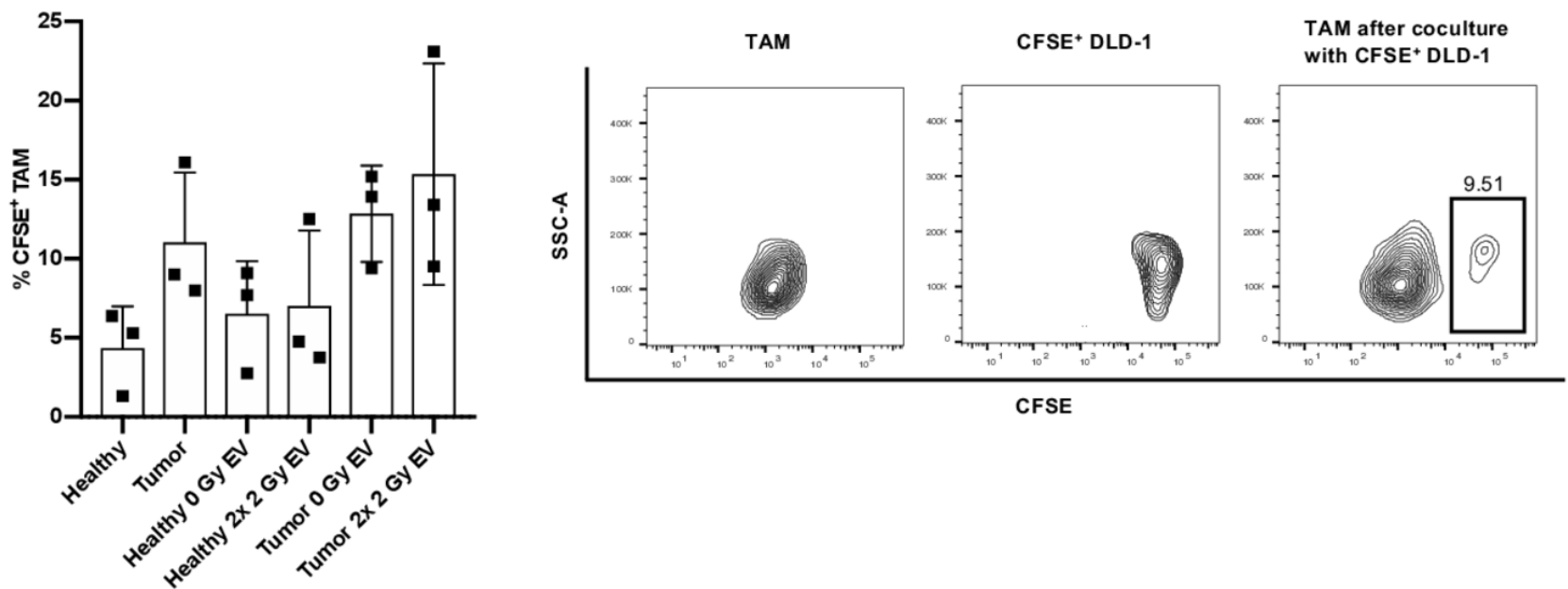

Figure 6 Polarization of macrophages can be facilitated by irradiated DLD-1-derived EV. (A) Nanotracker analysis of cancer EV. (B) Electron microscopic image of EV derived from DLD-1 cell line in widefield and close-up. EV display characteristic bilipid layer and size. (C) Western blot of characteristic and non-characteristic EV marker in DLD-1/HCT116 tumor cells and DLD-1/ HCT116-derived EV. (D) Expression of depicted markers on monocyte-derived CD14/CD11 b macrophages. (E) Expression of M2 (IL-4+IL-13) polarized CD14/CD11 b ${ }^{+}$macrophages after cultivation with EV of non-irradiated (0 Gy) and irradiated DLD-1 (2 $\times 2$ Gy), $n=10 .{ }^{* *} P<0.001,{ }^{* * *} p<0.0001$, by two-tailed paired Student's t-test. (F) Expression of CFSE in sorted TAM (CD11b, CD14, HLA-DR viable CD45) and representative flow cytometry plots of healthy colon/tumor after cultivation with EV of nonirradiated (0 Gy) and irradiated DLD-1 (2×2 Gy) in phagocytosis assay with CFSE ${ }^{+}$DLD-1, n=3, CFSE, carboxyfluorescein diacetate succinimidyl ester; EV,extracellular vesicles; Gy, Gray; HMGB1, high mobility group box 1; TAM, tumor-associated macrophages, TNF- $\alpha$, tumor necrosis factor- $\alpha$; IL, interleukin. 
as biopsies of tumors might not be representative for the tumor immune infiltrate, since the latter is heterogeneously distributed throughout the tumor tissue. ${ }^{42}$

Klug et al found that low-dose irradiation (0.5 Gy) induced an influx of $\mathrm{CD}^{+}{ }^{+} \mathrm{T}_{\text {cells. }}{ }^{24}$ In contrast, we did not observe a change in $\mathrm{T}$ cell count following irradiation but we cannot rule out the possibility of an alteration in the CD4/CD8 T cell ratio upon irradiation or the recruitment of $\mathrm{CD}^{+} \mathrm{T}$ cells at the cost of $\mathrm{CD} 4^{+} \mathrm{T}$ cells. However, we found that macrophages showed enhanced expression of HLA-DR, IL-12 p70 and IL-23 p19; factors, which can potentially stimulate $\mathrm{T}$ cell function. This observation is in line with a recent study in melanoma which demonstrated an increased infiltration of activated $\mathrm{T}$ cells after depletion of $\mathrm{CD}_{163^{+}}$macrophages resulting in tumor regression. ${ }^{43}$ In contrast, in a number of murine tumor models, irradiation induced an immunosuppressive macrophage phenotype. ${ }^{27-29}{ }^{44}$ In these models, macrophages inhibited T-cell activation. Our findings suggest that irradiation repolarizes macrophages to a Th1oriented phenotype which not just directly promotes proinflammatory macrophages but may be able to facilitate anticancer function indirectly via activating $\mathrm{T}$ cells. If this is relevant in vivo needs to be proven. The results of this study indicate that routinely applied short-course irradiation of human rectal cancer exerts an innate immunogenic effect. However, ex vivo and organotypic systems have limitations as they cannot monitor cells that potentially could be recruited into the tumors after treatment.

In TAM isolated from rectal cancer tissue PD-1 expression significantly decreased after ex vivo irradiation (figure 2C). This observation is in line with previous reports of PD-1 in macrophages inhibiting the ability to phagocyte in the cancer microenvironment and being therefore marker of an immunosuppressive phenotype. ${ }^{38}$ In contrast to TAM, PD-1 was not significantly altered in macrophages after coculture with $\mathrm{EV}$ of irradiated cancer cell lines (figure 6E). Although we use monocyte-derived macrophages as a surrogate to investigate the influences of EV, we propose, due to cell origin and environment, one should be careful to transfer conclusion from bloodderived macrophages to TAM.

TAM of in vivo irradiated tumors decreased (figure 3B), whereas the amount of TAM in ex vivo irradiated cancer samples was not significantly altered (figure 1C). This difference is most likely due to the fact that the cumulative irradiation dose in cancer patients was different (25 Gy vs $2 \mathrm{~Gy}$ ) compared with the irradiation dose applied in the ex vivo experiments (figures 1A and 3A). Besides direct accumulating cytotoxic effects on macrophages, irradiation may damage vascular structures and alter signaling of the tumor microenvironment.

Repolarization of macrophages towards proinflammation is one possible concept to inhibit protumoral functions of TAM. Other studies suggest targeting perivascular TAM populations which promote tumor revascularization and relapse through vascular endothelial growth factor release, and block TAM's M2-related properties pharmacologically via CXCR $4 .{ }^{45}$ After irradiation, bone-marrow derived $\mathrm{CD}_{11} \mathrm{~b}^{+}$cells expressing metalloprotease-9 (MMP-9) contribute to vascular remodeling. As a result, genetic depletion of MMP-9 in knockout mice abolished tumor growth, demonstrating MMP-9 from myeloid cells as a potential target in combination with radiotherapy. ${ }^{46}$ Another approach proposes the use of the chemotherapeutic drug trabectedin which is approved for soft tissue sarcomas. Trabectedin activates caspase 8 selectively in mononuclear phagocytes consequently inducing apoptosis in monocytes and TAM. ${ }^{47}$

One could hypothesize that the polarization of TAM to a pro-inflammatory M1-like phenotype is only a local phenomenon without measurable systemic outcomes and/ or that the magnitude of subsequent immunological effects is not strong enough for a sustained therapeutic improvement. However, the TAM related immune stimulation could support the local effects of short-course irradiation in preventing the spill of tumor cells locally due to surgical manipulations. This might render the immune-stimulatory aspect of irradiation to be therapeutically meaningful in preventing local recurrence.

Interestingly, we also demonstrated that the cell type specific polarization of TAM can be facilitated through EV isolated from irradiated DLD-1 cells (figure 6C). We identified HMGB1 in EV from irradiated tumor cells as a potential effector signal for the interaction of tumor cells with TAM. However, we did not provide a mechanism which proves HMGB1 to be relevant. Since irradiation failed to induce HMGB1 in EV isolated of HCT116 we conclude factors other than HMGB1 have an impact on macrophages' polarization state. Tumor cell-derived EV were previously shown to be involved in immunomodulation. ${ }^{48-50}$ Other reports demonstrated the induction of interferon-inducible genes and pro-inflammatory cytokines in macrophages through HMGB1 facilitating macrophage reprogramming towards the M1-like phenotype. $^{51}{ }^{52}$ Whether and how exosome-derived HMGB1 can directly induce irradiation-induced TAM polarization still needs to be proven.

Our data further indicate that clinically observed immune response to irradiation can be modeled by ex vivo cultures of tumor explants or OTA making these systems attractive for preclinical investigations to find conditions which further enhance the immunogenic effects of therapeutic strategies on the cancer environment. Our work additionally suggests that ex vivo systems can be potentially implemented in clinical routine, helping to facilitate patient oriented drug developments taking into account unique disease characteristics.

In summary, our data support the concept that irradiation in rectal cancer patients facilitates a distinct macrophage phenotype which is eventually able to directly and indirectly mediate anti-tumor immune responses.

Correction notice This article has been corrected since it was published. The author name 'Johannes Laengle' was incorrectly spelt as 'Johannes Längle' and 
the 'MD' suffix at the end of Michael Bergmann's name was removed. Additionally, affiliation 1 was updated to 'Division of General Surgery, Department of Surgery, Comprehensive Cancer Center, Medical University of Vienna, Vienna, Vienna, Austria'.

Acknowledgements Nanoparticle tracking analysis was done by Andreas Spittler, Core Facility Flow Cytometry \& Surgical Research Laboratories, Medical University of Vienna, Austria. Cryo-electron microscopy of EV was performed by Thomas Heuser at the EM Facility of the Vienna BioCenter Core Facilities GmbH, which acknowledges funding from the Austrian Federal Ministry of Education, Science and Research and the City of Vienna. Graphical abstracts created with BioRender.

Contributors VS and MB designed the study. VS, BW, JList and MT performed the experiments. JLängle and JS revised the manuscript. AB provided access to human samples. DU and HD consulted on the method of organotypic assays. GS consulted on the flowcytometric data. VS and MB wrote the manuscript.

Funding This work was supported by the Comprehensive Cancer Center (CCC) Grant, Vienna, Austria granted to VS.

Competing interests None declared.

Patient consent for publication Not required.

Ethics approval Studies involving patient material were performed according to the Declaration of Helsinki and approved by the local ethics committee of the Medical University of Vienna (1374/2014).

Provenance and peer review Not commissioned; externally peer reviewed.

Data availability statement All data relevant to the study are included in the article or uploaded as supplementary information.

Open access This is an open access article distributed in accordance with the Creative Commons Attribution Non Commercial (CC BY-NC 4.0) license, which permits others to distribute, remix, adapt, build upon this work non-commercially, and license their derivative works on different terms, provided the original work is properly cited, appropriate credit is given, any changes made indicated, and the use is non-commercial. See http://creativecommons.org/licenses/by-nc/4.0/.

\section{ORCID iDs}

Victoria Stary http://orcid.org/0000-0002-3854-9934

Brigitte Wolf http://orcid.org/0000-0003-2120-5614

Julia List http://orcid.org/0000-0002-4199-3198

Johannes Laengle http://orcid.org/0000-0003-4771-1398

Andrea Beer http://orcid.org/0000-0002-0726-1233

Johanna Strobl http://orcid.org/0000-0003-3606-2185

Georg Stary http://orcid.org/0000-0003-1746-4250

Helmut Dolznig http://orcid.org/0000-0002-6063-3585

Michael Bergmann http://orcid.org/0000-0001-8529-1166

\section{REFERENCES}

1 Reck M, Rodríguez-Abreu D, Robinson AG, et al. Pembrolizumab versus chemotherapy for PD-L1-positive non-small-cell lung cancer. N Engl J Med 2016;375:1823-33.

2 Le DT, Durham JN, Smith KN, et al. Mismatch repair deficiency predicts response of solid tumors to PD-1 blockade. Science 2017;357:409-13.

3 D'Angelo SP, Mahoney MR, Van Tine BA, et al. Nivolumab with or without ipilimumab treatment for metastatic sarcoma (alliance A091401): two open-label, non-comparative, randomised, phase 2 trials. Lancet Oncol 2018;19:416-26.

4 Apetoh L, Ghiringhelli F, Tesniere A, et al. Toll-Like receptor 4-dependent contribution of the immune system to anticancer chemotherapy and radiotherapy. Nat Med 2007;13:1050-9.

5 Deng L, Liang $\mathrm{H}, \mathrm{Xu} \mathrm{M}$, et al. Sting-Dependent cytosolic DNA sensing promotes radiation-induced type I interferondependent antitumor immunity in immunogenic tumors. Immunity 2014;41:843-52.

6 Twyman-Saint Victor C, Rech AJ, Maity A, et al. Radiation and dual checkpoint blockade activate non-redundant immune mechanisms in cancer. Nature 2015;520:373-7.

7 Deng L, Liang H, Burnette B, et al. Irradiation and anti-PD-L1 treatment synergistically promote antitumor immunity in mice. J Clin Invest 2014;124:687-95.

8 Dovedi SJ, Adlard AL, Lipowska-Bhalla G, et al. Acquired resistance to fractionated radiotherapy can be overcome by concurrent PD-L1 blockade. Cancer Res 2014;74:5458-68.
9 Pollard JW. Tumour-educated macrophages promote tumour progression and metastasis. Nat Rev Cancer 2004;4:71-8.

10 van Ravenswaay Claasen HH, Kluin PM, Fleuren GJ. Tumor infiltrating cells in human cancer. on the possible role of CD16+ macrophages in antitumor cytotoxicity. Lab Invest 1992;67:166-74.

11 Mantovani A. Cancer: Inflaming metastasis. Nature 2009;457:36-7.

12 Quail DF, Joyce JA. Microenvironmental regulation of tumor progression and metastasis. Nat Med 2013;19:1423-37.

13 Mosser DM, Edwards JP. Exploring the full spectrum of macrophage activation. Nat Rev Immunol 2008;8:958-69.

14 Biswas SK, Mantovani A. Macrophage plasticity and interaction with lymphocyte subsets: cancer as a paradigm. Nat Immunol 2010;11:889-96.

15 De Palma M, Mazzieri R, Politi LS, et al. Tumor-Targeted interferonalpha delivery by Tie2-expressing monocytes inhibits tumor growth and metastasis. Cancer Cell 2008;14:299-311.

16 Mills CD, Kincaid K, Alt JM, et al. M-1/M-2 macrophages and the Th1/Th2 paradigm. J Immunol 2000;164:6166-73.

17 Murray PJ, Wynn TA. Protective and pathogenic functions of macrophage subsets. Nat Rev Immunol 2011;11:723-37.

18 Gordon S, Martinez FO. Alternative activation of macrophages: mechanism and functions. Immunity 2010;32:593-604.

19 Sudan B, Wacker MA, Wilson ME, et al. A systematic approach to identify markers of distinctly activated human macrophages. Front Immunol 2015;6:253.

20 Allavena P, Sica A, Solinas G, et al. The inflammatory microenvironment in tumor progression: the role of tumor-associated macrophages. Crit Rev Oncol Hematol 2008;66:1-9.

21 Mantovani A, Bottazzi B, Colotta F, et al. The origin and function of tumor-associated macrophages. Immunol Today 1992;13:265-70.

22 Mantovani A, Allavena P. The interaction of anticancer therapies with tumor-associated macrophages. J Exp Med 2015;212:435-45.

23 Genard G, Lucas S, Michiels C. Reprogramming of tumor-associated macrophages with anticancer therapies: radiotherapy versus chemoand immunotherapies. Front Immunol 2017;8:828.

24 Klug F, Prakash H, Huber PE, et al. Low-Dose irradiation programs macrophage differentiation to an iNOS+/M1 phenotype that orchestrates effective T cell immunotherapy. Cancer Cell 2013;24:589-602.

25 Tsai C-S, Chen F-H, Wang C-C, et al. Macrophages from irradiated tumors express higher levels of iNOS, arginase-I and COX-2, and promote tumor growth. Int J Radiat Oncol Biol Phys 2007;68:499-507.

26 Dewan MZ, Vanpouille-Box C, Kawashima N, et al. Synergy of topical Toll-like receptor 7 agonist with radiation and low-dose cyclophosphamide in a mouse model of cutaneous breast cancer. Clin Cancer Res 2012;18:6668-78.

27 Jones KI, Tiersma J, Yuzhalin AE, et al. Radiation combined with macrophage depletion promotes adaptive immunity and potentiates checkpoint blockade. EMBO Mol Med 2018:10.

28 Crittenden MR, Cottam B, Savage T, et al. Expression of NF-kB p50 in tumor stroma limits the control of tumors by radiation therapy. PLoS One 2012;7:e39295.

29 Seifert L, Werba G, Tiwari S, et al. Radiation therapy induces macrophages to suppress T-cell responses against pancreatic tumors in mice. Gastroenterology 2016;150:1659-72.

30 Zitvogel L, Regnault A, Lozier A, et al. Eradication of established murine tumors using a novel cell-free vaccine: dendritic cell-derived exosomes. Nat Med 1998;4:594-600.

31 Gross JC, Chaudhary V, Bartscherer K, et al. Active Wnt proteins are secreted on exosomes. Nat Cell Biol 2012;14:1036-45.

32 Becker A, Thakur BK, Weiss JM, et al. Extracellular vesicles in cancer: cell-to-cell mediators of metastasis. Cancer Cell 2016;30:836-48

33 Chen G, Huang AC, Zhang W, et al. Exosomal PD-L1 contributes to immunosuppression and is associated with anti-PD-1 response. Nature 2018;560:382-6.

34 Widder J, Herbst F, Dobrowsky W, et al. Preoperative short-term radiation therapy (25 Gy, 2.5 Gy twice daily) for primary resectable rectal cancer (phase II). Br J Cancer 2005;92:1209-14.

35 Kramer N, Schmöllerl J, Unger C, et al. Autocrine WNT2 signaling in fibroblasts promotes colorectal cancer progression. Oncogene 2017;36:5460-72.

36 Unger C, Kramer N, Unterleuthner D, et al. Stromal-Derived IGF2 promotes colon cancer progression via paracrine and autocrine mechanisms. Oncogene 2017;36:5341-55.

37 EV-TRACK Consortium, Van Deun J, Mestdagh P, et al. EV-TRACK: transparent reporting and centralizing knowledge in extracellular vesicle research. Nat Methods 2017;14:228-32. 
38 Gordon SR, Maute RL, Dulken BW, et al. Pd-1 expression by tumourassociated macrophages inhibits phagocytosis and tumour immunity. Nature 2017;545:495-9.

39 Pinto ML, Rios E, Durães C, et al. The two faces of tumor-associated macrophages and their clinical significance in colorectal cancer. Front Immunol 2019;10:10.

40 Koelzer VH, Canonica K, Dawson H, et al. Phenotyping of tumorassociated macrophages in colorectal cancer: impact on single cell invasion (tumor budding) and clinicopathological outcome. Oncoimmunology 2016;5:e1106677.

41 Teresa Pinto A, Laranjeiro Pinto M, Patrícia Cardoso A, et al. lonizing radiation modulates human macrophages towards a proinflammatory phenotype preserving their pro-invasive and proangiogenic capacities. Sci Rep 2016;6:18765.

42 Galon J, Costes A, Sanchez-Cabo F, et al. Type, density, and location of immune cells within human colorectal tumors predict clinical outcome. Science 2006;313:1960-4.

43 Etzerodt A, Tsalkitzi K, Maniecki M, et al. Specific targeting of CD163 ${ }^{+}$TAMs mobilizes inflammatory monocytes and promotes $T$ cell-mediated tumor regression. J Exp Med 2019;216:2394-411.

44 Shiao SL, Ruffell B, DeNardo DG, et al. TH2-Polarized CD4(+) T Cells and Macrophages Limit Efficacy of Radiotherapy. Cancer Immunol Res 2015;3:518-25.
45 Hughes R, Qian B-Z, Rowan C, et al. Perivascular M2 macrophages stimulate tumor relapse after chemotherapy. Cancer Res 2015;75:3479-91.

46 Ahn G-O, Brown JM. Matrix metalloproteinase-9 is required for tumor vasculogenesis but not for angiogenesis: role of bone marrowderived myelomonocytic cells. Cancer Cell 2008;13:193-205.

47 Germano G, Frapolli R, Belgiovine C, et al. Role of macrophage targeting in the antitumor activity of trabectedin. Cancer Cell 2013;23:249-62.

48 Ye L, Zhang Q, Cheng Y, et al. Tumor-derived exosomal HMGB1 fosters hepatocellular carcinoma immune evasion by promoting TIM$1^{+}$regulatory B cell expansion. J Immunother Cancer 2018;6:145.

49 Zhang X, Shi H, Yuan X, et al. Tumor-Derived exosomes induce N2 polarization of neutrophils to promote gastric cancer cell migration. Mol Cancer 2018;17:146.

50 Qadir F, Aziz MA, Sari CP, et al. Transcriptome reprogramming by cancer exosomes: identification of novel molecular targets in matrix and immune modulation. Mol Cancer 2018;17:97.

51 Yanai $\mathrm{H}$, Ban T, Wang Z, et al. Hmgb proteins function as universal sentinels for nucleic-acid-mediated innate immune responses. Nature 2009:462:99-103.

52 Tian J, Avalos AM, Mao S-Y, et al. Toll-Like receptor 9-dependent activation by DNA-containing immune complexes is mediated by HMGB1 and RAGE. Nat Immunol 2007;8:487-96. 